\title{
Solarização do solo em casa-de-vegetação e campo para o controle de Rhizoctonia solani AG-4
}

\author{
Flávia Rodrigues Alves Patrício ${ }^{1}$, Hiroshi Kimati² ${ }^{2}$ João Tessarioli Neto ${ }^{3}$, Ademir Petenatti ${ }^{4}$, Benedito Camargo Barros ${ }^{1}$
}

${ }^{1}$ Instituto Biológico, Caixa Postal 70, CEP 13010-970, Campinas, SP, e-mail:flavia@biologico.sp.gov.br. ${ }^{2}$ Departamento de Entomologia, Fitopatologia e Zoologia, ESALQ-USP, CP 9, CEP 13418-900. Departamento de Produção Vegetal, ESALQ-USP, CP 9, CEP 13418-900, ${ }^{4}$ Departamento de Estatística, UNICAMP, Caixa Postal 6065, CEP 13083-970, Campinas, SP.

* Parte da tese de doutorado do primeiro autor.

Autor para correspondência: Flávia Rodrigues Alves Patrício

Data de chegada: 14/09/2005. Aceito para publicação em: 10/11/2006.

\section{RESUMO}

Patrício, F.R.A., Kimati, H., Tessarioli Neto, J., Petenatti, A. \& Barros, B.C. Solarização do solo em casa-de-vegetação e campo para o controle de Rhizoctonia solani AG-4. Summa Phytopathologica, v.33, n.3, p.245-251, 2007.

Os cultivos em ambientes protegidos apresentaram uma grande expansão na década de 1990 no Brasil. O solo desses locais pode, por ser intensa e sucessivamente cultivado, se tornar infestado por patógenos como Rhizoctonia solani, responsável por tombamento e podridão de raízes em muitas espécies de plantas. O presente trabalho avaliou o emprego da solarização, dentro e fora de uma casa-devegetação vedada com plástico transparente, para o controle de $R$. solani. Quatro experimentos foram realizados, dois no verão de 1997/ 1998 e outros dois no verão seguinte, 1998/1999, em Piracicaba, SP (latitude $22^{\circ} 42^{\prime}$ e longitude $47^{\circ} 38^{\prime}$ ). Bolsas de náilon contendo solo autoclavado misturado a grãos de trigo colonizados com $R$. solani AG-4 foram enterradas a 10 e a $20 \mathrm{~cm}$ de profundidade em parcelas solarizadas e não solarizadas, dentro e fora da casa-de-vegetação, sendo coletadas após 20,30 e 40 dias para os dois primeiros experimentos e 15,30 e 45 dias para o terceiro e quarto. Avaliou-se a viabilidade do patógeno após a recuperação dos grãos dos solos, por meio do plaqueamento destes em ágar-água, contando-se, dois dias depois, sob microscópio estereoscópio, os que apresentaram crescimento micelial característico de $R$. solani. Foi obtida a erradicação do patógeno após 20 e 30 dias de solarização na casa de vegetação e após 30 a 45 dias no campo, provavelmente porque houve menor perda de calor durante a noite no ambiente protegido, pois as temperaturas médias ( 40 a $45^{\circ} \mathrm{C}$, dependendo do experimento) e máxima $\left(49^{\circ} \mathrm{C}\right)$ dos solos solarizados às 15:00 horas, a $10 \mathrm{~cm}$ de profundidade, foram semelhantes nos dois ambientes. Nas parcelas não solarizadas da casa-de-vegetação o patógeno também perdeu a viabilidade, porém mais lentamente (40 dias de tratamento para sua erradicação) que nas parcelas solarizadas.

Palavras-chave adicionais: patógeno de solo, tombamento de plântulas, desinfestação de solo

\section{ABSTRACT}

Patrício, F.R.A., Kimati, H., Tessarioli Neto, J., Petenatti, A. \& Barros, B.C. Soil solarization under greenhouse and field conditions to the control of Rhizoctonia solani AG-4. Summa Phytopathologica, v.33, n.3, p.245-251, 2007.

Crops grown under protected environment have had a great expansion in Brazil in the decade of 1990. In such environments soil is intensively and successively used and it may become infested with soilborne plant pathogens, such as Rhizoctonia solani, responsible for seedling damping-off and root rots of several plant species. In the present work soil solarization was used to the control of $R$. solani under greenhouse and field conditions. Four experiments were carried out, two in the summer of 1997/1998 and the other two in 1998/ 1999 in Piracicaba city, São Paulo state, Brazil (latitude $22^{\circ} 42^{\prime}$ and longitude $47^{\circ} 38^{\prime}$ ). Nylon bags containing disinfested soil with propagules of $R$. solani AG4 (wheat grains previously colonized with the pathogen) were buried at 10 and $20 \mathrm{~cm}$ soil depth in solarized and non-solarized plots. After 20,30, and 40 days in the two first experiments and 15,30 , and 45 days in the third and fourth experiments, the bags were removed from the soil. The grains were collected from the soil of each bag and placed in water-agar Petri dishes. After two days of incubation, grains showing typical growth of $R$. solani mycelium were assessed. Eradication of $R$. solani was accomplished after 20 to 30 days of soil solarization inside the greenhouse and after 30 to 45 days in the field, probably because in the protected environment the heat loss was smaller at night, since at 15:00 $\mathrm{h}$ the soil temperatures were similar in the solarized soils of both environments; with maximum of $49^{\circ} \mathrm{C}$ and medium temperatures between 40 and $45^{\circ} \mathrm{C}$, at $10 \mathrm{~cm}$ soil depth. In the non-solarized soil of the greenhouse the pathogen also lost its viability, although more slowly (40 days of treatment) than in the solarized plots. 
No início da década de 1990 o cultivo protegido, especialmente de hortaliças, apresentou rápida expansão no Brasil (4). As culturas conduzidas nesses ambientes permitem obter elevada produtividade, precocidade, rendimento econômico e produtos de alta qualidade, além de proporcionar colheitas na entressafra (4). Os solos dos ambientes protegidos, entretanto, como são intensa e sucessivamente cultivados, podem se tornar infestados por patógenos como Rhizoctonia solani, agente causal de tombamento e podridões radiculares e no colo de diversas hortaliças e ornamentais (5). Esse fungo é de difícil controle, pois apresenta grande capacidade saprofítica e produz estruturas de resistência, os escleródios, que sobrevivem por longos períodos no solo (16).

Para o controle de $R$. solani recomenda-se a desinfestação de solos e de substratos para a produção de mudas com vapor, brometo de metila ou a aplicação de fungicidas nas sementes ou nas plântulas recém-emergidas, antes e depois do transplante (5). O brometo de metila apresenta as vantagens de necessitar de apenas uma semana para o tratamento e ter amplo espectro de ação (5). Entretanto, esse produto encontra-se entre os gases apontados como responsáveis pela redução da camada de ozônio da atmosfera (22), e, por esse motivo, programas em vários países têm procurado desenvolver técnicas alternativas para a sua substituição $(22,20)$.

Entre as técnicas que podem ser utilizadas para a desinfestação de solos e de substratos, especialmente em condições tropicais, encontrase a solarização, que consiste na colocação de um filme plástico transparente sobre o solo umedecido, durante o período do ano de maior radiação solar, com o objetivo de promover o aumento de sua temperatura $(15,24)$. Durante o processo, o solo atinge temperaturas letais nas camadas superficiais e subletais nas mais profundas a muitos fitopatógenos, pragas e plantas daninhas, que resultam em alterações microbiológicas, químicas e físicas e, freqüentemente, em aumento de produção das culturas $(1,11 ; 15,23,24)$. A solarização se mostrou eficiente para o controle de $R$. solani nas culturas do algodão e alface $(21,23)$. Em casas-de-vegetação, no sul da Grécia e Itália, a técnica também proporcionou o controle de vários fitopatógenos, como Verticillium dahliae, Pyrenochaeta terrestris, Fusarium oxysporum f.sp. basilici, e também $R$. solani, além de aumentos significativos na produção e qualidade das hortaliças produzidas nesses ambientes (2, $3,12,25)$. No Brasil, Lopes et al. (18) verificaram a redução na viabilidade de Pythium aphanidermatum após a aplicação da técnica em casa-de-vegetação.

Nos ambientes protegidos a radiação solar que atinge o solo é geralmente menor que em campo, entretanto, forma-se uma camada estática de ar entre a cobertura plástica da casa-de-vegetação e o filme plástico da solarização, que age como isolante térmica, e pode promover um aumento adicional na temperatura do solo (19). Também pode reduzir as oscilações de temperatura, favorecendo o acúmulo de temperaturas letais aos fitopatógenos no solo. Como conseqüência, o período de solarização pode ser reduzido ou a técnica pode ser empregada na época menos favorável do ano $(15,19)$, que em Campinas, SP se estende dos meses de março a outubro (10).

Como o custo de construção e manutenção das casas-de-vegetação é elevado, impondo o seu cultivo intensivo, a redução no período de solarização pode tornar a técnica não só uma alternativa efetiva, como economicamente viável para a desinfestação de solos em ambientes protegidos. Por essa razão, o presente trabalho avaliou o efeito da solarização, aplicada em uma casa-de-vegetação e no campo, em uma área externa próxima, para o controle de $R$. solani AG-4, verificando a possibilidade de redução no período necessário para o tratamento no ambiente protegido.

\section{MATERIAL E MÉTODOS}

Para a realização dos experimentos utilizou-se um isolado de $R$. solani do grupo de anastomose AG-4, obtido de feijoeiro, procedente do município de Pompéia, SP. O isolado foi mantido, durante a condução dos ensaios, em BDA (batata, dextrose, ágar), sendo as colônias repicadas semanalmente. $\mathrm{O}$ isolado apresentou a capacidade de formar escleródios rapidamente em condições de laboratório, 4 a 5 dias após a repicagem. Para a multiplicação do patógeno, discos de micélio de $R$. solani retirados das bordas de colônias, cultivadas em BDA, foram adicionados a grãos de trigo dispostos em Erlenmeyers, previamente umedecidos e autoclavados ( 1 hora a $120^{\circ} \mathrm{C}$, em 2 dias consecutivos). Os grãos foram incubados em ambiente de laboratório por sete dias, até serem recobertos pelo micélio do patógeno. Em seguida foram preparadas bolsas de tela de náilon contendo $250 \mathrm{ml}$ de solo autoclavado $\left(120^{\circ} \mathrm{C}\right.$ por 3 horas) e $10 \mathrm{~g}$ de grãos colonizados com o patógeno.

Quatro experimentos de solarização foram conduzidos nos verões de 1997/1998 e 1998/1999, em uma casa de vegetação coberta com filme plástico transparente $(150 \mathrm{~mm}$ de espessura com aditivo estabilizador de raios ultravioleta) e revestida lateralmente com sombrite, e também em local próximo em campo aberto. Os locais pertencem à área experimental do Departamento de Produção Vegetal da ESALQ-USP, em Piracicaba, SP (latitude 22 $42^{\prime}$ e longitude $47^{\circ}$ $\left.38^{\prime}\right)$.

Nos dois primeiros ensaios, efetuados nos períodos de 18/12/97 a 26/01/98 e de 05/02 a 16/03/1998, uma área da casa-de-vegetação (14 $\mathrm{x} 8 \mathrm{~m})$ teve as paredes laterais vedadas com plástico transparente (100 $\mathrm{mm}$ de espessura), com o objetivo de aumentar a temperatura no seu interior. Uma parte dessa área $(7 \times 7 \mathrm{~m})$ foi solarizada e outra, de igual tamanho, permaneceu sem cobertura plástica. A 30 metros da casa-devegetação foi preparada uma área semelhante em campo aberto. As bolsas contendo os propágulos do patógeno foram dispostas de maneira casualizada sobre as áreas a serem solarizadas ou não, dentro e fora da casa-de-vegetação, mantendo uma distância mínima de $40 \mathrm{~cm}$ das bordas, sendo enterradas a 10 e a $20 \mathrm{~cm}$ de profundidade. $\mathrm{O}$ solo foi umedecido até próximo à capacidade de campo e a solarização foi aplicada com um filme plástico transparente (100 $\mu \mathrm{m}$ de espessura). As bordas do filme plástico foram enterradas a aproximadamente 20 $\mathrm{cm}$ de profundidade. Durante a condução dos experimentos as parcelas não solarizadas foram umedecidas periodicamente. Três bolsas de cada parcela e de cada profundidade foram retiradas aos 20, 30 e 40 dias após o início dos experimentos, sendo em seguida levadas ao laboratório, para a verificação da viabilidade do patógeno.

O terceiro e o quarto experimentos foram realizados nos períodos de 29/01 a 14/03/1999 e de 28/02 a 13/04/1999, respectivamente, em outra área da mesma casa-de-vegetação ( 28 x 8 m), que também foi vedada lateralmente com plástico transparente. A área foi dividida em quatro blocos (14 x 3,5 m), tendo cada bloco uma parcela solarizada ( 7 X 3,5 m) e outra não. Uma área externa localizada a 10 metros da casade-vegetação, foi preparada e dividida da mesma forma. As bolsas contendo os propágulos do patógeno foram dispostas ao acaso sobre as parcelas e, como nos experimentos anteriores, enterradas a 10 e a $20 \mathrm{~cm}$ de profundidade. Uma bolsa de cada sub-parcela e profundidade foi coletada aos 15,30 e 45 dias após o início dos experimentos, sendo em seguida levada ao laboratório para verificar a viabilidade do patógeno. Para a coleta das bolsas, o filme plástico que cobria cada parcela solarizada foi levantado com cuidado em local próximo à bolsa a ser coletada, a bolsa foi retirada e a borda do plástico foi novamente enterrada a $20 \mathrm{~cm}$ de profundidade. Como o processo foi efetuado rapidamente, não houve perda considerável de calor durante a retirada das bolsas. 
Durante a solarização as temperaturas dos solos foram registradas por meio de termômetros de solo (de mercúrio), dispostos no centro das parcelas, a 10 e a $20 \mathrm{~cm}$ de profundidade, às 8:00 e 15:00 horas nos dois primeiros experimentos, e apenas às 15:00 horas no terceiro e quarto ensaios.

As bolsas coletadas em todos os ensaios foram levadas ao laboratório, onde o solo de cada uma foi peneirado para a retirada manual dos grãos de trigo previamente colonizados com $R$. solani. Estes foram lavados, secos em papel de filtro esterilizado e colocados em placas de Petri contendo ágar-água e $0,2 \%$ de sulfato de estreptomicina (10 grãos por placa, 5 placas por bolsa). Dois dias após a incubação em ambiente de laboratório, as placas foram observadas em microscópio estereoscópio, verificando-se a presença de hifas características de $R$. solani, que indicaram a sobrevivência do patógeno. Calculou-se a porcentagem de grãos contendo hifas viáveis de R. solani.

Nos dois primeiros experimentos, a análise estatística dos dados foi realizada no programa SAS - sistems for linear models (17), utilizando-se um modelo fatorial $2 \times 2 \times 2 \times 3$, sendo os fatores: ambiente (dentro e fora da casa de vegetação); solarização, (com e sem), profundidade de colocação das amostras $(10$ e $20 \mathrm{~cm})$ e período de solarização (20, 30 e 40 dias), tendo como repetições as três bolsas coletadas de cada parcela.

Para a análise estatística do terceiro e quarto ensaios, blocos, solarização, cobertura e profundidade foram hierarquizados em relação ao ambiente, utilizado o PROC GLM do programa SAS -Sistems for linear models (17). A comparação entre os períodos e as interações entre períodos e demais fatores foram analisadas como medidas repetidas no tempo, comparando-se as médias pelo valor de F obtido no teste de Wilks-Lambda.

\section{RESULTADOS E DISCUSSÃO}

Nos dois primeiros experimentos, a solarização promoveu a erradicação de $R$. solani AG-4, a $20 \mathrm{~cm}$ de profundidade, após 20 e 40 dias de tratamento na casa de vegetação e no campo, respectivamente, (Figura 1). No primeiro e segundo ensaios o patógeno também foi erradicado no solo não solarizado do ambiente protegido após 30 e 40 dias de solarização, respectivamente (Figura 1). No terceiro experimento, a solarização resultou na erradicação dos propágulos de R. solani após 30 dias de tratamento dentro da casa-de-vegetação e 45 dias no campo (Figura 2). Também houve redução na viabilidade do fungo nas áreas não solarizadas da casa de vegetação, insuficiente, porém, para causar sua erradicação. No quarto experimento, a erradicação do patógeno ocorreu apenas após 45 dias de tratamento no campo, mas após 45 dias de tratamento na casa-de-vegetação, alguns propágulos ainda estavam viáveis na profundidade de $20 \mathrm{~cm}$ (Figura 2). Nesse experimento, a redução na viabilidade do patógeno foi pequena na área não solarizada do ambiente protegido. Assim como nos presentes experimentos, outros autores em outros países também obtiveram o controle de $R$. solani ao empregarem a solarização em campo aberto $(21)$ e em casas de vegetação $(7,12)$.

No primeiro e segundo experimentos, ocorreram 11 e 18 dias de precipitação durante a solarização enquanto as temperaturas máximas do ar foram semelhantes, 31,8 e $30,4{ }^{\circ} \mathrm{C}$ (médias do período) para o primeiro e segundo ensaio, respectivamente. $\mathrm{O}$ menor número de dias com precipitação, em que não ocorre aquecimento do solo, pode explicar porque o patógeno perdeu a viabilidade mais rapidamente nos tratamentos solarizados do primeiro ensaio (Figura 1). No terceiro e quarto ensaios houve 24 e 11 dias com chuvas e as temperaturas máximas do ar (médias do período) foram de 30,6 e $31,2{ }^{\circ} \mathrm{C}$, respectivamente. Embora tenha chovido mais no terceiro ensaio, o patógeno perdeu a viabilidade de maneira semelhante no terceiro e quarto experimentos (Figura 2), provavelmente porque o período de solarização em que ocorreu a erradicação do patógeno, 30 dias foi suficientemente longo para proporcionar o acúmulo de temperaturas letais a $R$. solani nos tratamentos solarizados.

Em todos os experimentos verificou-se redução na viabilidade dos propágulos do patógeno enterrados nas áreas não solarizadas, causada, provavelmente, pela exposição dos mesmos às condições do ambiente, como chuvas, calor, e pelos mecanismos naturais de supressividade do solo, como a atuação de microrganismos antagônicos. Os grãos, ao serem retirados do solo e incubados, apresentaram, além de $R$. solani, fungos dos gêneros Fusarium, Penicillium, Trichoderma e Mucor.

A redução na viabilidade de $R$. solani verificada nas áreas solarizadas e não solarizadas do ambiente protegido foi proporcional às temperaturas registradas nos solos durante a solarização (Figura 1), o que era esperado, pois a temperatura é a variável que mais influi no processo de desinfestação do solo $(15,24)$. Nos dois primeiros experimentos, as temperaturas médias e máximas observadas no solo solarizado do ambiente protegido pela manhã foram 2 a $3{ }^{\circ} \mathrm{C}$ superiores às do campo, indicando menor perda de calor durante a noite nessa condição (Tabela 1). Esse fato, provavelmente, foi responsável pela redução no período de tratamento necessário para a erradicação do patógeno na casa-de-vegetação (Figura 1), especialmente porque as temperaturas médias e máximas dos solos solarizados à tarde foram semelhantes nos dois ambientes $\left(45,6\right.$ e $\left.45,3^{\circ} \mathrm{C}\right)$.

No terceiro e quarto ensaios, as temperaturas médias foram menores nos solos solarizados do ambiente protegido (Tabela 1), provavelmente porque uma área maior da casa-de-vegetação foi utilizada $\left(224 \mathrm{~m}^{2}\right)$, sendo mais difícil manter totalmente vedada uma área maior desse ambiente. Como conseqüência, o patógeno perdeu a viabilidade mais lentamente nesses experimentos que nos anteriores (Figuras 1 e 2). No último ensaio o patógeno não foi erradicado no solo solarizado e perdeu apenas parte da viabilidade na parcela não solarizada do ambiente protegido. Nesse experimento, as temperaturas registradas nos solos solarizados e não solarizados da casa-de-vegetação foram menores (Tabela 1), provavelmente por causa de rachaduras nos plásticos da cobertura e das laterais (usados para vedação) do ambiente protegido, que ocorreram 15 dias após o início do ensaio, em decorrência de uma chuva de granizo e tempestade de vento. Esse fato demonstrou que vedar as casas-de-vegetação, especialmente as semelhantes a esta, durante a solarização, pode ser uma prática importante para uma maior eficiência do tratamento.

Nos presentes experimentos, as temperaturas médias (entre 40,0 e $45,6^{\circ} \mathrm{C}$ ) e máximas (entre 49,3 e $55,6^{\circ} \mathrm{C}$ ) registradas às 15:00 horas nos solos solarizados da casa-de-vegetação a $10 \mathrm{~cm}$ de profundidade (Tabela 1), foram semelhantes às obtidas em ambientes protegidos na Grécia $(2,25)$. As temperaturas observadas às 15:00 horas nos tratamentos solarizados dentro e fora da casa-de-vegetação foram semelhantes, embora se esperassem temperaturas maiores no ambiente protegido. Na Itália, Garibaldi \& Gullino (6), encontraram temperaturas $9{ }^{\circ} \mathrm{C}$ (12 cm de profundidade) superiores nas parcelas solarizadas de uma casa-de-vetação coberta com vidro que no campo aberto. Essas diferenças ocorreram, possivelmente porque esse tipo de casa-devegetação é mais transparente que a utilizada nos presentes experimentos. Essa última, semelhante às empregadas por grande parte dos produtores em cultivo protegido no Brasil, tem as laterais revestidas com sombrite. Embora a área recoberta com sombrite estivesse vedada com plástico transparente, pode ter havido redução na penetração dos 

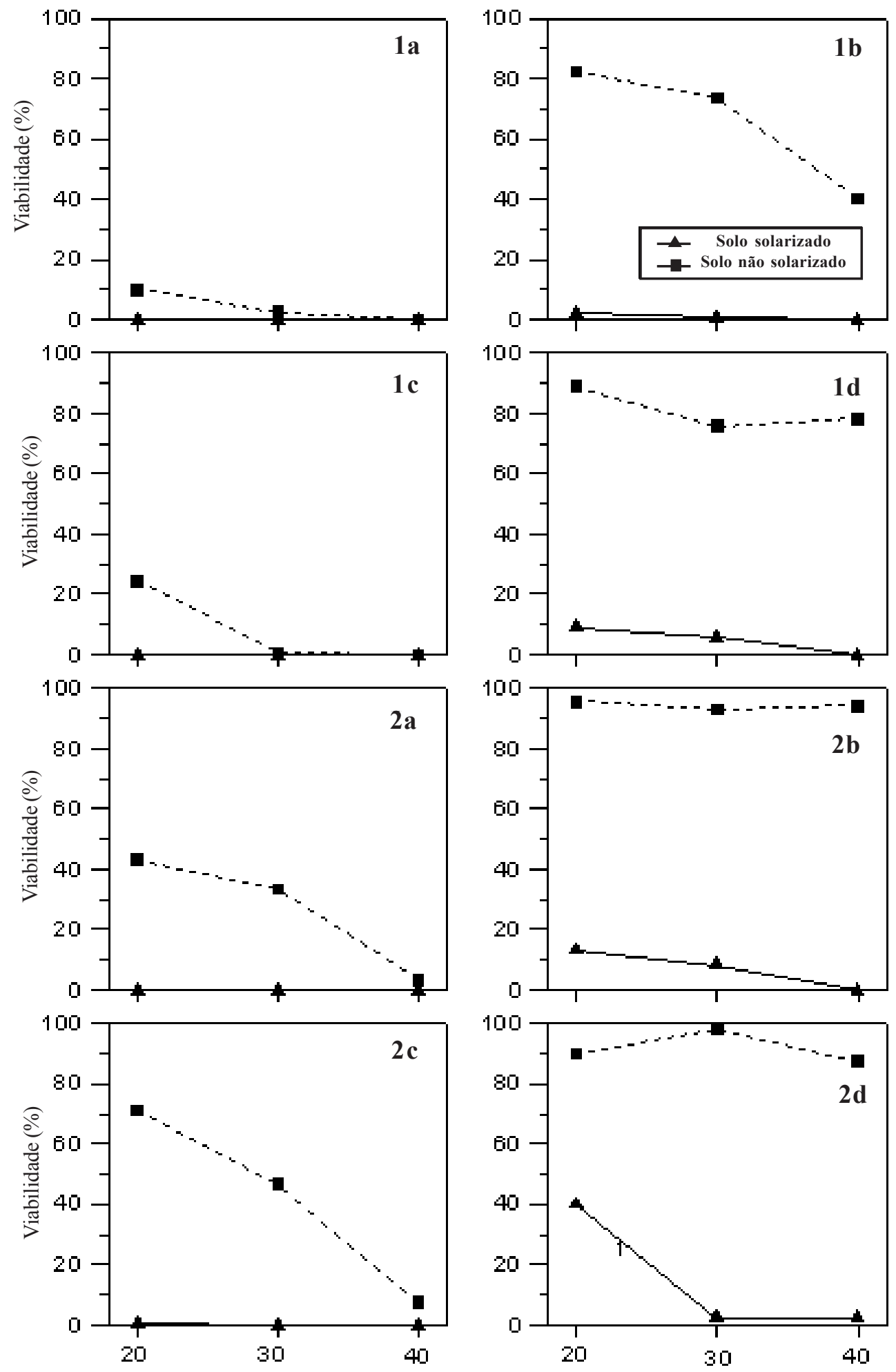

Período de solarização (dias)

Figura 1. Viabilidade de propágulos de Rhizoctonia solani AG-4, avaliada pela porcentagem de grãos de trigo com crescimento micelial do fungo, retirados de bolsas enterradas em solos solarizados e não solarizados, aos 20, 30 e 40 dias após o início dos experimentos. Primeiro e segundo experimentos, realizados nos períodos de 18/12/97 a 26/01/98 e 05/02 a 16/03/98, respectivamente, em Piracicaba, SP. Primeiro experimento, (1a) casa-de-vegetação, $10 \mathrm{~cm}$ de profundidade; (1b) campo, $10 \mathrm{~cm}$ profundidade; (1c) casa-de-vegetação, $20 \mathrm{~cm}$ de profundidade; (1d) campo, $20 \mathrm{~cm}$ profundidade; Segundo experimento, (2a) casa-de-vegetação, $10 \mathrm{~cm}$ de profundidade; (2b) campo, $10 \mathrm{~cm}$ profundidade; (2c) casa-de-vegetação, $20 \mathrm{~cm}$ de profundidade; (2d) campo, $20 \mathrm{~cm}$ profundidade. 

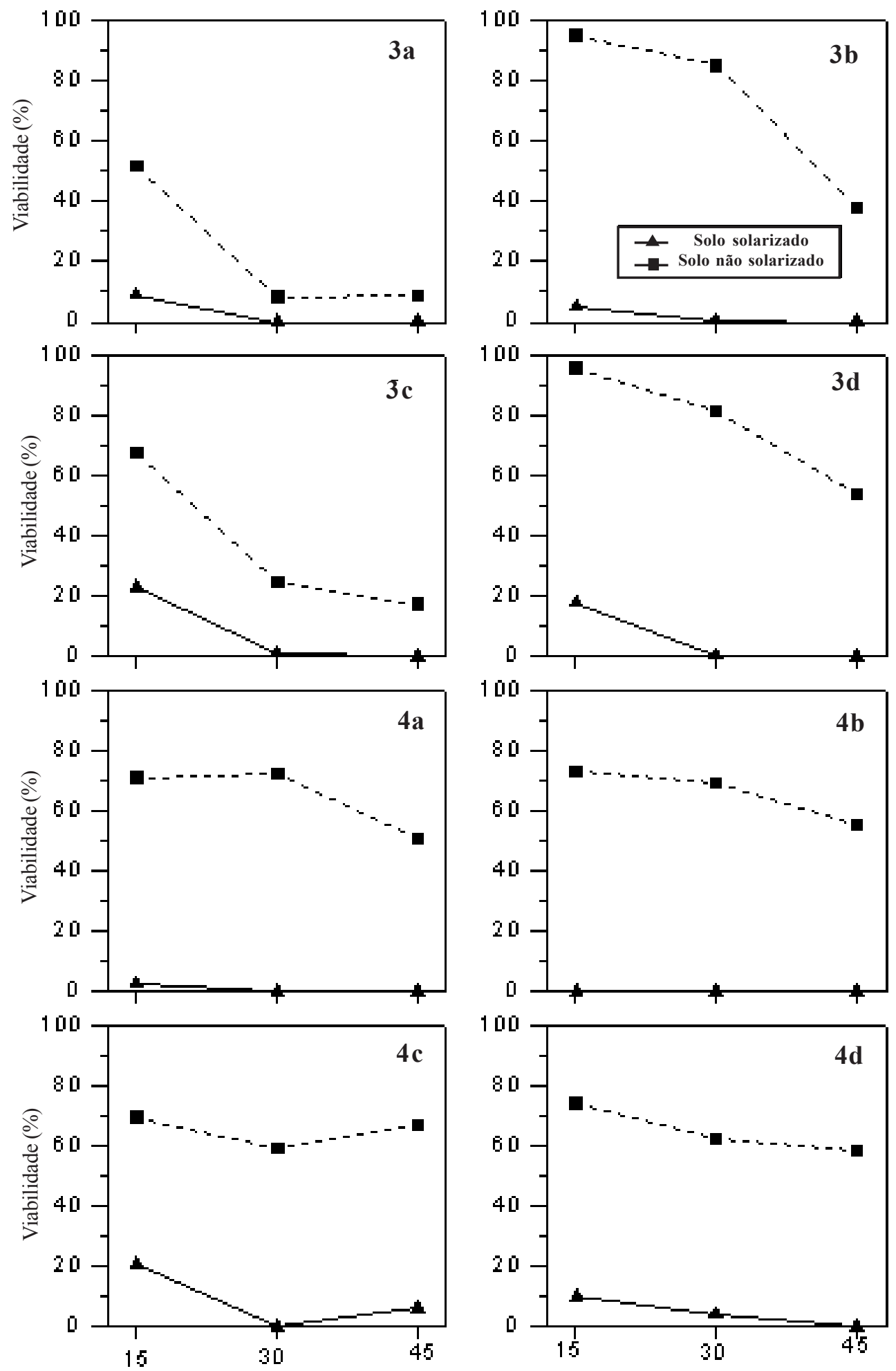

Período de solarização (dias)

Figura 2.Viabilidade de propágulos de Rhizoctonia solani AG-4, avaliada pela porcentagem de grãos de trigo com crescimento micelial do fungo, retirados de bolsas enterradas em solos solarizados e não solarizados, aos 15, 30 e 45 dias após o início dos experimentos. Terceiro e quarto experimentos, realizados nos períodos de 29/01 a 14/03/1999, e de 28/02 a 13/04/1999, respectivamente, em Piracicaba, SP. Terceiro experimento, (3a) casa-de-vegetação, 10 cm de profundidade; (3b) campo, $10 \mathrm{~cm}$ profundidade; (3c) casa-de-vegetação, $20 \mathrm{~cm}$ de profundidade; (3d) campo, $20 \mathrm{~cm}$ profundidade; Quarto experimento, (4a) casa-de-vegetação, $10 \mathrm{~cm}$ de profundidade; (4b) campo, $10 \mathrm{~cm}$ profundidade; (4c) casa-de-vegetação, $20 \mathrm{~cm}$ de profundidade; (4d) campo, $20 \mathrm{~cm}$ profundidade. 


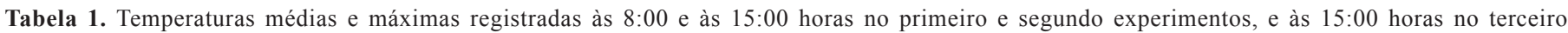

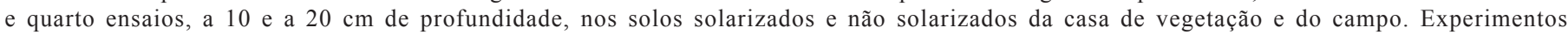
conduzidos em Piracicaba, SP.

Temperaturas $\left({ }^{\circ} \mathrm{C}\right)$

\begin{tabular}{|c|c|c|c|c|c|c|c|c|c|c|c|c|}
\hline \multirow{3}{*}{$\frac{\text { Profundidades }}{\text { Solarização }}$} & \multicolumn{6}{|c|}{$10 \mathrm{~cm}$} & \multicolumn{6}{|c|}{$20 \mathrm{~cm}$} \\
\hline & \multicolumn{3}{|c|}{ Solo solarizado } & \multicolumn{3}{|c|}{ S. não solarizado } & \multicolumn{3}{|c|}{ Solo solarizado } & \multicolumn{3}{|c|}{ Solo não solarizado } \\
\hline & Méd ${ }^{1}$ & Máx ${ }^{2}$ & & Méd. & Máx. & & Méd. & Máx. & & Méd. & Máx. & \\
\hline $\begin{array}{l}\text { 10 } \text { Experimento }^{3} \\
\text { 8:00 h Casa-de-vegetação } \\
\quad \text { Campo }\end{array}$ & 36,0 & $\begin{array}{l}39,4 \\
33,2\end{array}$ & 37,2 & 33,0 & $\begin{array}{l}36,0 \\
27,0\end{array}$ & 30,2 & 37,9 & $\begin{array}{l}41,3 \\
35,8\end{array}$ & 37,4 & 34,1 & $\begin{array}{l}37,4 \\
29,1\end{array}$ & 31,4 \\
\hline $\begin{array}{c}\text { 15:00 h Casa-de-vegetação } \\
\text { Campo }\end{array}$ & 45,6 & $\begin{array}{l}55,4 \\
45,3\end{array}$ & 52,0 & 41,4 & $\begin{array}{l}45,5 \\
35,6\end{array}$ & 41,2 & 40,8 & $\begin{array}{l}47,2 \\
39,7\end{array}$ & 43,4 & 37,2 & $\begin{array}{l}41,0 \\
31,4\end{array}$ & 33,1 \\
\hline $\begin{array}{l}\text { 20 Experimento }{ }^{4} \\
\text { 8:00 h Casa-de-vegetação } \\
\quad \text { Campo }\end{array}$ & 34,4 & $\begin{array}{l}38,6 \\
31,2\end{array}$ & 36,7 & 31,1 & $\begin{array}{l}35,0 \\
25,0\end{array}$ & 28,8 & 36,4 & $\begin{array}{l}40,8 \\
33,4\end{array}$ & 38,0 & 32,4 & $\begin{array}{l}35,5 \\
27,0\end{array}$ & 31,1 \\
\hline $\begin{array}{c}\text { 15:00 h Casa-de-vegetação } \\
\text { Campo }\end{array}$ & 43,4 & $\begin{array}{l}52,1 \\
41,0\end{array}$ & 47,4 & 37,7 & $\begin{array}{l}44,0 \\
32,1\end{array}$ & 38,5 & 39,4 & $\begin{array}{l}44,6 \\
36,9\end{array}$ & 42,6 & 35,0 & $\begin{array}{l}38,6 \\
29,0\end{array}$ & 32,0 \\
\hline $\begin{array}{l}\text { 30 Experimento }{ }^{5} \\
\text { 15:00 h Casa-de-vegetação } \\
\quad \text { Campo }\end{array}$ & 42,5 & $\begin{array}{l}49,9 \\
42,0\end{array}$ & 48,5 & 36,1 & $\begin{array}{l}41,5 \\
31,9\end{array}$ & 38,3 & 37,3 & $\begin{array}{l}40,6 \\
36,7\end{array}$ & 42,6 & 32,5 & $\begin{array}{l}34,9 \\
29,2\end{array}$ & 31,4 \\
\hline $\begin{array}{l}4^{\circ} \text { Experimento }^{6} \\
\text { 15:00 h Casa-de-vegetação } \\
\text { Campo }\end{array}$ & 41,1 & $\begin{array}{l}49,3 \\
44,9\end{array}$ & 49,3 & 35,9 & $\begin{array}{l}40,5 \\
33,5\end{array}$ & 38,1 & 37,8 & $\begin{array}{l}41,2 \\
39,2\end{array}$ & 41,5 & 32,4 & $\begin{array}{l}35,2 \\
30,2\end{array}$ & 33,1 \\
\hline
\end{tabular}

${ }^{1}$ Temperatura media;

${ }^{2}$ Temperatura maxima;

${ }^{1}$ Primeiro experimento, realizado no período de 18/12/1997 a 26/01/1998;

${ }^{2}$ Segundo experimento, realizado no período de 5/02 a 16/03/1998;

3 Terceiro experimento, realizado no período de 29/01 a 14/03/99;

${ }^{4}$ Quarto experimento, realizado no período de 28/02 a 13/04/99.

raios solares, que resultou no menor aquecimento do solo solarizado.

Períodos de 20 a 30 dias de solarização no ambiente protegido foram suficientes para promover o controle de $R$. solani na região de Piracicaba, SP, considerando as duas profundidades estudadas. Entretanto, em experimentos realizados na Itália foram necessários 40 dias de solarização para o controle deste patógeno em canteiros elevados utilizados para a produção de manjericão em uma casa-de-vegetação (12). Em campo aberto, a erradicação do patógeno ocorreu após 40 dias de solarização nos dois primeiros e no quarto experimentos e após 30 dias no terceiro ensaio. Períodos menores foram suficientes para o controle de $R$. solani em outros locais, 14 dias para a cultura do algodão na Califórnia (21) e três semanas para a desinfestação de substrato utilizado para o plantio de gerbera na Austrália (13).

Ocorreram interações significativas entre ambiente e solarização nos três primeiros experimentos (Probabilidade $>\mathrm{F}=0,0001 ; 0,0001$ e 0,0001 para o primeiro, segundo e terceiro experimentos, respectivamente), provavelmente, porque nas áreas não solarizadas do ambiente protegido o patógeno foi controlado pela solarização, chegando a ser erradicado, mas no campo o mesmo perdeu apenas parte da viabilidade. No terceiro ensaio, os períodos (Probabilidade $>$ $\mathrm{F}=0,0001)$ e as interações entre períodos e ambiente (Probabilidade $>\mathrm{F}=0,0010)$ e períodos e solarização (Probabilidade $>\mathrm{F}=0,0001$ ) foram significativas, possivelmente porque o patógeno perdeu a viabilidade mais rapidamente no tratamento não solarizado da casa de vegetação, a 10 e a $20 \mathrm{~cm}$ de profundidade (Figura 4), do que nas parcelas não solarizadas do campo. No quarto experimento, não ocorreram interações entre ambiente e solarização, provavelmente porque o patógeno, assim como no campo, não perdeu a viabilidade nas parcelas não solarizadas do ambiente protegido, o qual não permaneceu vedado durante todo o transcorrer do ensaio.

Considerando os quatro experimentos realizados neste estudo, não houve efeito significativo da profundidade de colocação das amostras e também não ocorreu interação entre esse fator e os demais, com exceção do primeiro (Probabilidade $>\mathrm{F}=0,0218$ ) e último períodos do terceiro e do quarto ensaios (Probabilidade $>\mathrm{F}=0,0248$ ). Entretanto, a erradicação do patógeno foi mais rápida nas menores profundidades (Figuras 1 e 2), o que era esperado, pois as camadas mais superficiais do solo também são as mais aquecidas durante o tratamento. Neste trabalho as temperaturas foram 4 a $4,5^{\circ} \mathrm{C}$ superiores a $10 \mathrm{~cm}$ do que a $20 \mathrm{~cm}$ de profundidade. $\mathrm{O}$ fator período foi significativo para o primeiro (Probabilidade $>\mathrm{F}=0,0221$ ), terceiro (Probabilidade $>\mathrm{F}=0,0001$ ) e quarto (Probabilidade $>\mathrm{F}=0,0003$ ) experimentos, provavelmente porque, como esperado, o patógeno perdeu a viabilidade durante o tratamento.

Segundo Katan (14), os dados obtidos em experimentos de solarização que utilizam amostras de solo artificialmente infestadas ou contendo propágulos de patógenos, dispostas em bolsas de náilon e enterradas em várias profundidades, precisam ser interpretados com cuidado, mas podem fornecer importantes informações com relação ao período do ano ideal, ao tempo necessário para o tratamento, à 
sensibilidade do patógeno à temperatura e também quanto à profundidade em que o mesmo pode ser controlado. Nos presentes experimentos, verificou-se que a solarização promoveu o controle de $R$. solani após 20 e 30 dias de tratamento no ambiente protegido e após 30 a 45 dias no campo. A redução no período de solarização verificada na casa-de-vegetação ocorreu provavelmente porque, como esta se encontrava vedada, houve menor perda de calor durante a noite nesse ambiente, possibilitando maior acúmulo de temperaturas letais a $R$. solani nessa condição. Também como conseqüência da vedação, o patógeno perdeu a viabilidade nas parcelas não solarizadas do ambiente protegido, porém, de maneira mais lenta que nas áreas solarizadas.

As temperaturas registradas às 15:00 horas nos solos solarizados foram similares nos dois ambientes e as mesmas foram semelhantes às verificadas em outros experimentos de solarização conduzidos no Brasil, nos quais foi obtido o controle de outros fitopatógenos, como Sclerotium rolfsii, Verticillium dahliae, e Sclerotinia minor $(8,9,23) \mathrm{e}$ também de Rhizoctonia solani (23). Por esta razão, sugere-se que, assim como em campo, a solarização pode ser uma alternativa à aplicação do brometo de metila para a desinfestação de solos em ambientes protegidos no Brasil. O período de tratamento em casasde-vegetação pode ser reduzido, o que implica em menor período de imobilização da área e pode aumentar a viabilidade da aplicação da técnica para os produtores, que utilizam o solo de maneira muito intensiva nessa condição.

\section{REFERÊNCIAS BIBLIOGRÁFICAS}

1. Barros, B.C.; Patrício, F.R.A.; Lopes, M.E.B.M.; Freitas, S.S.; Sinigaglia, C.; Malavolta, V.M.A.; Tessarioli Neto, J.; Ghini, R. Solarização do solo com filmes plásticos com e sem aditivo estabilizador de luz ultravioleta. Horticultura Brasileira, Brasília, v.22, n.2, p. 253-259, 2004

2. Bourbos, V.A.; Skoudriakis, M.T. Soil solarization for the control of Verticillium wilt of greenhouse tomato. Phytoparasitica, Jerusalem, v. 24, n.4, p.277-280, 1996.

3. Cartia, G.; Cipriano, T. Effect of solarization and fumigants on soil borne pathogens of pepper in greenhouse. Acta Horticulturae, Leuven, v. 255, p.111-115, 1989.

4. Della Vechia, P.T.; Koch, P.S. História e perspectivas da produção de hortaliças em ambiente protegido no Brasil. Informe Agropecuário, Belo Horizonte, v.20, n.200/201, p.5-10, 1999.

5. Flechter J.T. Diseases of greenhouse plants. Essex:Longman Group Limited, 1984. 335 p.

6. Garibaldi, A.; Gulino, M.L. Soil solarization in southern European countries, with emphasis on soilborne disease control of protected crops. In: Katan, J.; DeVay, J.E. Soil solarization. Boca Raton: CRC, 1991. cap.16, p.227-235.

7. Garibaldi, A.; Tamietti, G. Solar heating: recent results obtained in northern Italy. Acta Horticulturae, Leuven, v. 255, p.125-129, 1989.

8. Ghini, R.; Bettiol, W.; Caldari JR., P. Solarização do solo para o controle de Sclerotium rolfsii em feijoeiro. Summa Phytopathologica, Jaboticabal, v.23, p.143-145, 1997.
9. Ghini, R.; Bettiol, W.; Souza, N.L. Solarização do solo para o controle de Verticillium dahliae em berinjela. Fitopatologia Brasileira, Brasília, v.17, p.384-388, 1992.

10. Ghini, R.; Paraíba, L.C.; Lima, M.W.P. Determinação de período para solarização do solo na região de Campinas, SP. Summa Phytopathologica, Jaboticabal, v.20, n.2, p.131-133, 1994.

11. Ghini, R.; Patrício, F.R.A.; Souza, M.D.; Sinigaglia, C.; Barros, B.C.; Lopes, M.E.B.M., Tessarioli Neto, J.; Cantarella, H. Efeito da solarização sobre as propriedades físicas, químicas e biológicas de solos. Revista Brasileira de Ciência do Solo, Viçosa, v.27, p.71-79, 2003.

12. Gulino, M.L.; Minuto, A.; Garibaldi, A. Improved method of bench solarization for the control of soilborne diseases in basil. Crop Protection, London, v.17, n.6, p.497-501, 1998.

13. Kaewruang, W.; Sivasithamparm K.; Hardy, G.E. Effect of solarization of soil within plastic bags on root rot of gerbera (Gerbera jamesonii L.). Plant and Soil, The Hage, v.120, p.303-306, 1989.

14. Katan, J. Soil solarization: integrated control aspects. In: Hall, R. (Ed.) Principles and practices of managing soilborne plant pathogens. St. Paul: APS Press, 1996. p. 213-236.

15. Katan, J.; DeVay, J.E. Soil solarization; historical perspectives, principles and uses. In: Katan, J.; DeVay, J.E. Soil solarization. Boca Raton: CRC Press, 1991. cap.2, p.24-37.

16. Latorre, B.A. Cucurbitaceae, enfermedades. In: Latorre, B; Vaughan, M.A.; Aguilar, P.G. Plagas de las hortalizas - manual de manejo integrado. Santiago: FAO, 1990. cap.4, p.155-180.

17. Littel, R.C.; Freund, R.J.; Spector, P.C. SAS System for linear models, 3 ed. Cary: SAS Institute, 1991, p.329.

18. Lopes, M.E.B.M.; Ghini, R.; Tessariolli, J.; Patrício, F.R.A. Solarização do solo para o controle de Pythium spp. na cultura do pepino em cultivo protegido. Summa Phytopathologica, Botucatu, v.26, p.224-227, 2000.

19. Mahrer, Y. Physical principles of solar heating of soils by plastic mulching in the field and in glasshouses and simulation models. In: Katan, J.; DeVay, J.E. Soil solarization. Boca Raton: CRC Press, 1991. cap.6, p.76-86.

20. Noling, J.W. The practical realities of alternatives to methyl bromide: concluding remarks. Phytopathology, St. Paul, v. 92, n.12, p.1373-1375, 2002

21. Pullman, G.S.; DeVay, J.E.; Garber, R.H.; Weinhold, A.R. Soil solarization: effects on verticillium wilt of cotton and soilborne populations of Verticillium dahliae, Pythium spp., Rhizoctonia solani and Thielaviopsis basicola. Phytopathology, St. Paul, v.71, n.9, p.954-959, 1981.

22. Ristaino, J.B.; Thomas, W. Agriculture, methyl bromide, and the ozone hole. Can we fill the gaps? Plant Disease, St. Paul, v.81, n.9, p. 964-977, 1997.

23. Sinigaglia, C.; Patrício, F.R.A.; Ghini, R., Malavolta, V.M.A.; Tessarioli, J.; Freitas, S.S. Controle de Sclerotinia minor, Rhizoctonia solani e plantas daninhas pela solarização do solo e sua integração com controle químico. Summa Phytopathologica, Jaboticabal, v. 27, p.229-235, 2001

24. Souza, N.L. Solarização do solo. Summa Phytopathologica, Botucatu, v.20, n.1, p.3-15, 1994.

25. Tjamos, E.C.; Karapapa, V.; Bardas, D. Low cost application of soil solarization in covered plastic houses for the control of Verticillium wilt in tomatoes in Greece. Acta Horticulturae, Leuven, v. 255, p.139-149, 1989. 